Faculdade

de Ciências Econômicas UFRGS
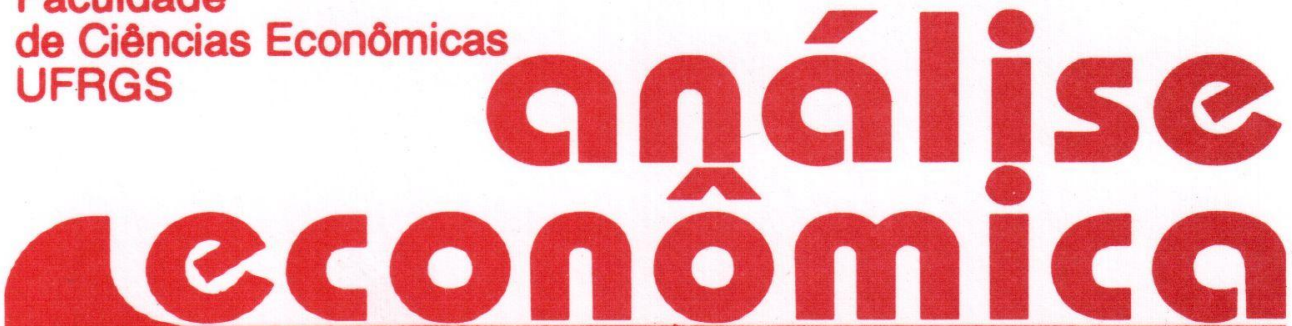

- A teoria NEOCLÁssica (PURA) E A TEORIA NEO-AUSTRIACA FRENTE AO LEGADO CARTESIANO Eleutério F. S. Prado

- MEdidAs de CONCENTRAÇÃo INDUSTRIAL: UMA RESENHA Marcelo Resende

- SISTEMA TRIBUTÁRIO E IMPOSTO ÚNICO SOBRE TRANSAÇÕES Ricardo Letizia Garcia

- ECONOMIA DO NORDESTE: TENDÊNCIAS DAS ÁREAS DINÂMICAS Policarpo Lima

- Custos e BENEFÍcIos DA INTEGRAÇÃO DO GRUPO ANDINO Marco Antônio Montoya

- Pós-graduAÇÃo EM ECONOMIa NOS ESTADOS UNIDOS DA AMÉRICA Egon Roque Fröhlich

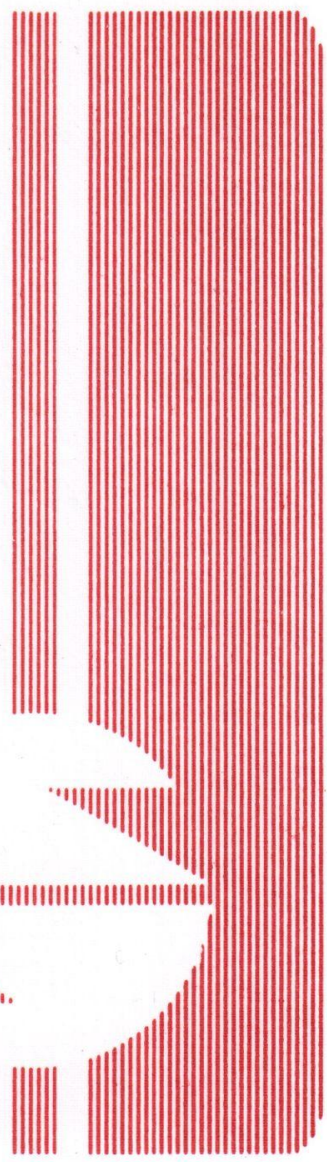


UNIVERSIDADE FEDERAL DO RIO GRANDE DO SUL

Reitor Prof Hélgio Henrique Casses Trindade

FACULDADE DE CIÊNCIAS ECONÓMICAS

Diretor Prof Pedro Cézar Dutra Fonseca

CENTRO DE ESTUDOS E PEQUISAS ECONÔMICAS

Diretor Prof. Paulo Alexandre Spohr

DEPARTAMENTO DE CIÉNCIAS ECONÓMICAS

Chefe: Prof Achyles Barcelos da Costa

CURSO DE PÓS-GRADUAÇÃO EM ECONOMIA

Coordenador Prof Nali de Jesus de Souza

CURSO DE PÓS-GRADUAÇÃO EM ECONOMIA RURAL

Coordenador. Prof Atos Freitas Grawunder

CONSELHO EDITORIAL: Achyles Barcelos da Costa, Aray Miguel Feldens, Atos Freitas Grawunder, Carlos Augusto Crusius, Fernando Ferrari Filho, Juvir Luiz Mattuella, Marcelo Savino Portugal, Maria Imilda da Costa e Silva, Nali de Jesus de Souza, Nuno R. L. de Figueiredo Pinto, Otília Beatriz K. Carrion, Paulo Alexandre Spohr, Pedro Cezar Dutra Fonseca, Roberto Camps Moraes, Valter José Stülp, David Garlow (Wharton Econometrics Forecasts Association, E.U.A.), Edgar Augusto Lanzer (UFSC), Eleutério Prado (USP), Fernando de Holanda Barbosa (FGV/RJ), Gustavo Franco (PUC/RJ), João Rogério Sanson (UFSC), Joaquim Pinto de Andrade (UnB), Juan H. Moldau (USP), Werner Baer (Univ. de Illinois, E.U.A.).

COMISSÃO EDITORIAL: Atos Freitas Grawunder, Pedro Cezar Dutra Fonseca, Marcelo Savino Portugal, Roberto Camps Moraes.

EDITOR: Nali de Jesus de Souza

SECRETARIA Cláudia Porto Silveira, Jeferson Luis Bittencourt e Vanete Ricachescki (revisão de textos)

FUNDADOR: Prof Antônio Carlos Santos Rosa

Os materiais publicados na revista Análise Econômica são da exclusiva responsabilidade dos autores. É permitida a reprodução total ou parcial dos trabalhos, desde que seia citada a fonte. Aceita-se permuta com revistas congêneres. Aceitam-se, também, livros para divulgação, elaboração de resenhas e recensōes. Toda correspondência, material para publicação (vide normas na terceira capa), assinaturas e permutas devem ser dirigidos ao seguinte destinatário:

PROF. NALI DE JESUS DE SOUZA

Revista Análise Econômica

Av. João Pessoa, 52

CEP 90040-000 PORTO ALEGRE - RS, BRASIL

E-MAIL: NALI@VORTEXUFRGS.BR

Telefones: (051) 316-3348 e 316-3440

Fax: (051) 225-1067 


\title{
O SISTEMA TRIBUTÁRIO BRASILEIRO E A PROPOSTA DO IMPOSTO ÚNICO SOBRE TRANSAÇÕES
}

Ricardo Letizia Garcia**

\begin{abstract}
SINOPSE
Avaliando o quadro de crise por que passa o Estado brasileiro e a urgência de reformas estruturais que melhorem a sua eficiêcia e redesenhem o seu papel na economia, o artigo busca examinar a proposta de reforma tributária que visa a criação de um imposto único. Neste exame, busca-se quantificar, a partir de um modelo matemático, o impacto deste imposto sobre os preços finais, a receita advinda com a sua aplicação e o grau de regressividade do sistema com a sua implantação.
\end{abstract}

\section{INTRODUÇÃO}

Existe um certo consenso entre os diversos setores da sociedade da urgência de uma reforma no Estado brasileiro que incluiria, como elemento principal, uma reforma fiscal. Muito desse consenso se dá porque nos últimos anos o setor público tem apresentado uma acentuada instabilidade, não podendo agir como alavancador de um desenvolvimento econômico permanente. Colocando de outra forma, pode-s€ dizer que as medidas e choques econômicos adotados pelos sucessivos governos não se mostram consistentes para resolver os problemas estruturais da economia brasileira

Assim, estamos tendo oportunidade de acompanhar com maior intensidade os debates que se sucedem a respeito do tema da refurma fiscal. Reforma fiscal que busca, entre outras coisas, definir uma nova estrutura tributária que traduza-se no aumento da arrecadação fiscal, na ampliação de sua base tributária e diminuição da

* Este artigo foi elaborado com base na dissentação de mestrado do autor ( $O$ Imposto Único sobre Transações e as suas repercussões na Economia), defendida no Curso de Pós-Graduação de Economia da UFRGS, em 1994

Mestre em Economia pela UFRGS. Professor de Economia da Universidade de Passo Fundo, RS.

\begin{tabular}{|c|l|}
\hline $\begin{array}{c}\text { Cód. AEA } \\
351\end{array}$ & $\begin{array}{l}\text { Palavras-chave: } \\
\text { Imposto único, sistema tributário e Brasil }\end{array}$ \\
\hline
\end{tabular}

\begin{tabular}{|l|l|l|l|}
\hline ANÁLISE ECONÓMICA & ANO 12 & março e setembro/94 & p. 34-54 \\
\hline
\end{tabular}


carga tributária para alguns segmentos da sociedade, na racionalização de sua estrutura e no combate aos sonegadores.

Diante deste quadro, buscou-se neste artigo fazer um breve resumo dos principais problemas de nossa atual estrutura tributária, examinando de forma mais minuciosa a proposta do Imposto Único sobre Transaçōes e as repercussões que teriamos nos preços setoriais da economia e na receita do Estado com a sua implantação.

\section{OS PROBLEMAS DO ATUAL SISTEMA TRIBUTÁRIO}

A última reforma tributária importante no País ocorreu em 1967. Os impostos sobre transações foram substituídcs pelo Imposto sobre Circulação de Mercadorias (ICM) em nível estadual e pelo Imposto sobre Produtos Industrializados (IPI) em nivel federal. A receita dos impostos sobre a propriedade foi transferida aos municípios sendo que o Imposto Territorial Rural (ITR) permaneceu sob o controle do Governo Federal para atender objetivos de política econômica entre outros que não fossem os de arrecadação.

Esta composição de tributos mostrou-se adequada naquele periodo e nas condições econômicas vividas nesta época. Contudo, com a instabilidade e o desequilíbrio econômico apresentado nos últimos anos, este conjunto de tributos revelaram-se "deteriorados" e sem condições de reverter este processo. Esta deterioração pode ser observada sob diversos pontos.

Um primeiro ponto observado diz respeito ao conteúdo de impostos que não podem ser rebatidos na exportação (especialmente os que incidem sobre o lucro, 0 faturamento e a folha de pagamentos). No Brasil este conteúdo é mais elevado do que em outros paises; do mesmo modo, os produtos importados contêm menos impostos que os produtos brasileiros, e estes podem se tornar negativamente protegidos se as tarifas aduaneiras forem rebaixadas para os niveis praticados pelos paises mais abertos (Zockun, 1992, p.3).

Existe uma quase unanimidade de opinião quanto a complexidade das regras e normas tributárias existentes no atual sistema tributárin brasileiro. Isto tem dificultado ao contribuinte o cumprimento das obrigações com o fisco, implicando muitas vezes um auinento dos niveis de evasão fiscal através da sonegação, da corrupção e do crescimento da economia informal.

O peso exagerado dos tributos sobre os eventos da produção é também sempre uma crítica presente quando avaliamos a atual estrutura tributária. Esta carga excessiva tem estimulado empresas menores ou menos estruturadas a praticar a sonegação dos tributos exigidos, permanecendo como contribuinte, via de regra, apenas os setores mais organizados, de quem o fisco procura extrair o máximo de receita, aumentando alíquotaș para compensar a parcela que não consegue extrair dos demais. É um círculo vicioso, pois à medida que aumentamos as alíquotas há quase que automaticamente uma diminuição da base de contribuintes tornando-se sem efeito esta medida em termos de receita fiscal. O pior de tudo é que isto está minando a capacidade de crescimento dos setores mais dinâmicos da economia brasileira (Decálogo, 1991, p.7-10 e Zockun, 1992, p.3). 
Parece claro que neste último parágrafo residem as maiores críticas à atual estrutura tributária brasileira. Neste sentido, tributaristas e técnicos ligados à área tributária partem do consenso de que a eficiência de um conjunto de tributos está na associação de aliquotas baixas a uma ampla base de incidência. Essa base será tanto maior quanto menor for o número de isenções e exceções.

A necessidade de uma reforma fiscal pode também ser argumentada a partir da tendência observada desde a última reforma tributária com a criação de novos tributos que incidem especialmente sobre o valor das transações. O economista Carlos Alberto Longo apresenta com clareza esta nova tendência.

Depois de 1967, os fatos geradores dos principais impostos se concentraram no fluxo de renda e no valor adicionado. Durante 25 anos, contudo, criaram-se novos tributos que incidem especialmente sobre o vaior das transaçōes. São notórios os defeitos dessa fonte: regressividade fiscal e a distorção alocativa. Aos poucos, desapareceram os impostos únicos (IUCL, IUEE, IUM etc.), e diminuiu a parcela do IPI e a do IR sobre as pessoas físicas, no total das receitas. Ao mesmo tempo, foram introduzidos novos impostos e contribuições ao sabor das circunstâncias. A perda de arrecadação derivada do esvaziamento dos tributos tradicionais (IR,IPI,únicos ...) atingiu, aproximadamente, $4 \%$ do PIB nas últimas décadas. Mas, essa perda foi compensada pelo aumento de contribuiçōes parafiscais (IOF, FINSOCIAL, PIS-PASEP, contribuição sobre o lucro) (Longo, 1991, p.9).

Esta mudança na incidência com a criação de noves tributos trouxe insatisfação e descontentamento aos mais diversos segmentos da sociedade brasileira. Aumentando a regressividade fiscal do sistema tributário e distribuindo de forma injusta a carga tributária, os atuais tributos atingem principalmente os assalariados de classe média e as empresas organizadas (Decálogo, 1991, p.10).

Essas distorções, além de ferir o princípio tributário da eqüidade ${ }^{1}$, têm dificultado os programas de estabilização econômica propostos pelo governo, pois induz a um descumprimento das obrigações tributárias por parte dos contribuintes, aumentando a sonegação e a evasão dos recursos fiscais

Estes problemas aliados a outros, como a complexidade das regras tributárias, demonstram a incapacidade do atual sistema tributário de resoiver o desequilibrio financeiro estrutural apresentado pelos governos federais e estaduais ao longo dos últimos anos

\section{O IMPOSTO ÚNICO SOBRE TRANSAÇÕES (IUT)}

Diante dos problemas, cada vez mais graves, e das deficiências do atual sistema tributário brasileiro, surgiu no debate entre as diversas propostas de reforma tributária,

1 A eqüidade num tributo é um dos principios básicos orientadores de uma boa estrutura tributária. Buscar uma distribuição eqüitativa da carga tributária entre os contribuintes deve ser um élemento sempre presente nas politicas de governo. Ao se aplicar a eqüidade num sistema tributário objetivase não apenas evitar uma maior concentração da riqueza, mas também reduzi-la. 
uma nova proposta que vem adquirindo cada vez mais espaço. Esta linha defende que uma reforma fiscal mais radical, alterando toda a estrutura básica de impostos hoje existente não impossibilitaria que o governo aumentasse a sua arrecadação tributária racionalizando e simplificando o atual sistema fiscal arrecadador.

Esse novo sistema fiscal sustentado basicamente por um único imposto atenderia, segundo seus seguidores, os princípios de justiça tributária, alcançando a progressividade desejada, ampliando o número de contribuintes com a participação da economia informal no pagamento dos tributos e, por fim, também diminuindo os níveis de sonegação hoje existentes.

Para atender a estas premissas e solucionar grande parte dos desajustes fiscais hoje verificados, essa nova estrutura tributária consistiria fundamentalmente na implantação de um Imposto Único que utilizasse a transação monetária como a base de tributação de forma a maximizar a base tributária, minimizando as aliquotas marginais (Albuquerque, 1991b, p.56)

A alíquota deste imposto seria de $2 \%$ sobre o valor de cada transação ocorrida no sistema bancário dividida igualmente em $1 \%$ para o devedor ₹ $1 \%$ para o credor. Para evitar que as transaçōes efetuadas ern moeda corrente ficassem isentas, Albuquerque propõe uma aliquota diferenciada de $4 \%$ sobre todo o saque ou depósito de moeda corrente no sistema bancário. Assim, toda vez que ocorresse um pagamento de um agente econômico a outro, dentro do sistema bancário, i.é, através da emissão de um cheque, ordem de pagamento, saque eletrônico etc., estará caracterizada a transação e, sobre este fato gerador incidiria o imposto (Cunha, 1092, p. 10).

Pela proposta de Albuquerque, todos os impostos que apresentassem características fiscais, ou seja, impostos cuja finalidade principal é de arrecadação de recursos deveriam ser substituídos pelo Imposto Único. Permaneceriam apenas os tributos que têm características extrafiscais, ou seja, tributos que não tenham apenas a finalidade arrecadatória, sendo também instrumentos de regulação econômica ou estejam vinculados à prestação de serviços. Assim, impostos como o Imposto Territorial Rura! (ITR) e o Imposto sobre comércio exterior não seriam extintos, pois atuam de maneira importante na regulação das atividades econômicas. Do mesmo modo, o Imposto sobre Propriedade Territorial Urbana (IPTL') permaneceria, pois historicamente tem se caracterizado como imposto vinculado à prestação de serviços públicos locais

\subsection{O mecanismo de incidência do imposto}

Com a aplicação deste imposto, o contribuinte pagará $1 \%$ dos seus rendimentos ao recebê-los e $1 \%$ ao gastá-los; presumindo que, neste processo de recebimento e gasto do rendimento auferido pelo individuo à transação, tenha se realizado através de algum documento na rede bancária.

Contudo, estes $2 \%$ de impostos pagos pelo contribuintes será apenas uma parte do imposto a the ser cobrado. Esta parte é a última parcela incidente do imposto, que o indivíduo percebe mais facilmente, por que recaiu diretamente. A carga tributária total que incidirá sobre o contribuinte será embutida ao longo dos processos de produção das mercadorias consumidas durante um período de tempo. Estas parcelas 
intermediárias que incidem sobre o consumidor são chamadas de parcela indireta do imposto Único.

Sendo a parcela indireta do Imposto Único a mais significativa da carga tributária incidente sobre os agentes econômicos, deve-se enfatizar a necessidade de analisar cada transação em separado para detectar nela, segundo o tipo de mercado envolvido na transação (através de um exame das elasticidades de oferta e procura de cada insumo ou produto final), que percentual do imposto recairá para o consumidor e para o produtor de determinada mercadoria.

Assim, como não há uma clara definição quanto à carga tributária incidente sobre cada produto na economia torna-se duvidosa a afirmação de Albuquerque de que contribuintes com maior renda consumirão um número maior de produtos sofisticados que teoricamente apresentam mais etapas no processo de produção sendo em conseqüencia sujeitos a uma tributação mais elevada.

\subsection{A arrecadação com o IUT}

Outra controvérsia importante quando se fala do Imposto Único é a arracadação que seria alcançada com a sua aplicação. Em defesa do IUT, Albuquerque argumenta que este provavelmente aumentaria o número de contribuintes do fisco.

No Brasi!, segundo dados do IBGE, $27 \%$ das pessoas ocupadas não têm carteira de trabalho assinada. Essa informalidade contratual pressiona os integrantes do mercado formal por contribuições mais elevadas, determinando um círculo vicioso que faz o governo buscar novas fontes de arrecadação, o que apenas induz à expansão ainda mais acelerada da economia marginal no Brasil. Neste sentido, a implantação do IUT também poderia incorporar a enorme parcela da economia informal e dos sonegadores, pois também se utilizam do setor bancário (Albuquerque, 1992, p. 2).

Todavia, até mesmo neste ponto, o IUT suscita dúvidas. Apesar de ser apresentado como um imposto insonegável, críticos deste imposto indagam quanto aos possiveis efeitos sobre a arrecadação com os ajustamentos dos agentes econômicos que poderão ocorrer, a partir de sua aplicação. Cabe aqui lembrar que uma transação que não envolver o sistema bancário não é alcançada pclo imposto não se constituindo, portanto, em sonegação. Esta parte não tributável pode ocorrer via uma desintermediação financeira, com o estímulo à posse de moeda estrangeira, num maior controle das contas bancárias pelos contribuintes e nas empresas, pela concentração mais ordenada das contas a pagar. O risco de uma queda na arrecadação derivada destes ajustamentos cria um certo desconforto enitre tributaristas e técnicos do governo que vêem a impossibilidade de reação e da adoção de medidas por parte do Estado.

Salientado os principais aspectos do IUT e o debate em torno dos sEus pontos mais polêmicos, analisam-se nas próximas seções do artigo a incidência, receita e eqüidade quie seriam obtidas com a sua aplicação.

\section{O MODELO NO CÁLCULO DO IMPACTO DO IUT NOS PREÇOS}


Apresentaremos nesta seção a formulação adotada para o cálculo do impacto do Imposto Único sobre os preços finais na economia. $O$ instrumental utilizado neste trabalho consistiu, fundamentalmente, nas tabelas contábeis básicas retiradas da Matriz de Relações Intersetoriais para o Brasil no ano de 1975 e elaborada pelo IBGE na versão mais agregada em que os 123 setores produtivos e 261 produtos foram agrupados em 9 setores e 10 produtos, respectivamente. Estas tabelas serviram como fonte exclusiva para elaboração dos resultados mostrados ${ }^{2}$

A agregação destes setores obedeceu a classificação do IBGE, que os dividiu em três grandes setores: Agropecuária, Indústria e Serviços. A Agropecuária abrangeu o setor de Agropecuária e Extrativa Vegetal. Na Indústria procurou-se distinguir os grupamentos mais homogêneos: Extrativa Mineral; Metal-Mecânica; Química; Agroindústria; Outros setores da Indústria de Transformação e Construção Civil. Quanto aos Serviços, destacou-se apenas o setor comércio e transporte dos demais. Por fim, a cada setor foi associado um produto (IBGE, 1987, p.33).

Os dados básicos são dispostos em tabelas de produção e de insumos a partir dos quais, adotando-se hipóteses específicas, podem ser construidos modelos de relações intersetoriais. A utilização deste modelo permitirá a avaliação dos impactos do novo imposto sobre os preços.

Partindo das identidades contábeis e das hipóteses estabelecidas sobre o padrão de inter-relacionamento dos setores produtivos, pode-se deduzir uma matriz de impacto - matriz de coeficientes diretos e indiretos ou matriz inversa de Leontieff - que relaciona alterações exógenas da demanda final com o nivel de produção (IBGE, 1987, p.33-35). Neste estudo, a matriz de impacto se fará necessária para o cálculo da incidência do Imposto Único sobre os preços setoriais.

Para a obtenção desta matriz multiplicamos a tabela de Insumos dos Setores Produtivos e Demanda Final ${ }^{3}$ (produto $x$ setor) pela tabela de Produção ${ }^{4}$ (setor $x$ produto), calculada em percentuais. Esta matriz pode ser chamada de matriz $A$ de coeficientes técnicos de produção, ou ainda, de matriz de coeficientes técnicos de

2 As tabelas apresentadas pela Matriz de Relações Intersetoriais na produção de bens e serviços constituem uma forma de organização dos dados de diferentes setores da economia, de modo a evidenciar a origem e o destino dos bens e serviços produzidos no pais e importados num dado ano. Explicitam as relações de dependência no interior do sistema produtivo, detalhando a estrutura de custos e a composição da produção dos setores que o integram e discriminando para os diversos agentes da demanda final, os produtos e serviços consumidos (IBGE, 1987, p.29, 33). A publicação da Matriz de Relaçöes Intersetoriais para o ano de 1975 foi escolhida por ser a última publicação que reproduz as tabelas contábeis básicas numa versão agregada.

3 A tabela de Insumos dos Setores Produtivos e Demanda Final apresenta na linha o destino de cada produto, valorado a preços básicos por setor produtivo e categoria de demanda final. Nas colunas têm-se a estrutura de custos dos setores produtivos e a procedência setorial da renda $e$, também, a composição por produtos da demanda final. (IBGE, 1987, p.34).

4 A tabela de Produção contêm os valores, a preços básicos, da produção nacional dos produtos, segundo os setores, em milhões de cruzeiros de 1975 (IBGE, 1987, p.33). 
insumos nacionais. Esta matriz de coeficientes técnicos de produção (matriz A) pode ser apresentada na forma de setores $\mathrm{x}$ setores ou produtos $\mathrm{x}$ produtos ${ }^{5}$

A matriz de coeficientes técnicos interprodutos mostra a demanda (impacto) direta que cada produto (indicado nas colunas) exerce sobre si mesmo e os demais produtos (indicados nas linhas), em função de aumento de uma unidade monetária na sua produção como mostra a tabela $1 .{ }^{6}$

\section{TABELA 1 - MATRIZ DE COEFICIENTES TÉCNICOS}

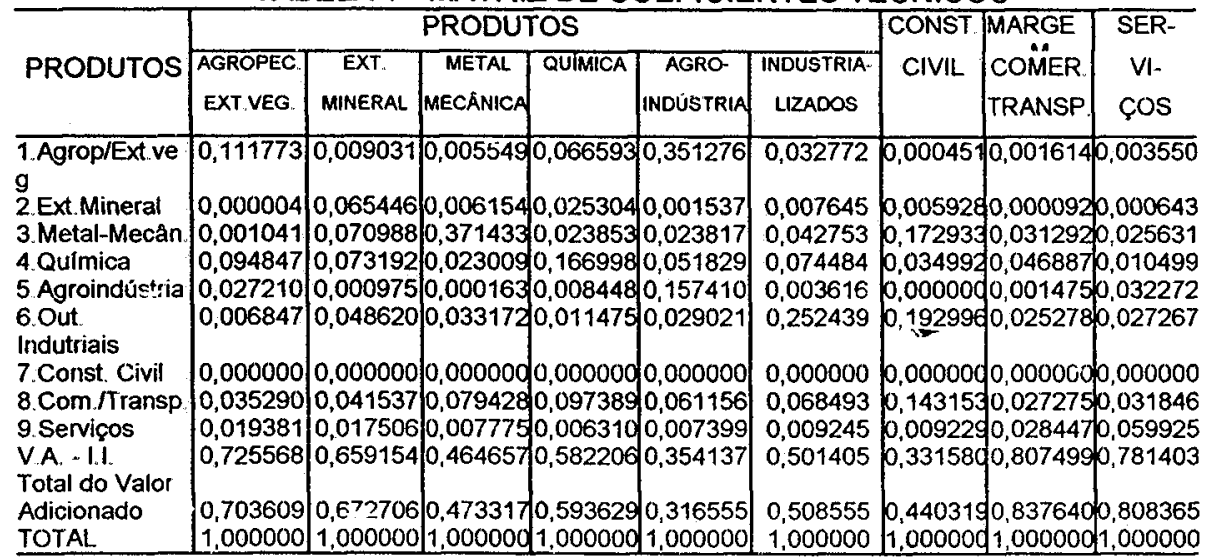

Fonte: Dados brutos da matriz do IBGE

Cada elemento da matriz de coeficientes técnicos $\left(a_{j i j}\right)$ indica a parcela da produção do selor $i$ absorvida por unidade de produção do setor $j$.

Com a matriz de coeficientes técnicos se obtém a solução geral do modelo estático básico de insumo-produto desenvolvido por Leontieff:

$$
\begin{aligned}
& a_{11} x_{1}+a_{12} x_{2}+\ldots+a_{1 n} \ddot{n}+y_{1}=x_{1} \\
& a_{21} x_{1}+a_{22} x_{2}+\ldots+a_{2 n} x_{n}+y_{2}=x_{2} \\
& \ldots \quad \ldots \quad \ldots \ldots \ldots=. .
\end{aligned}
$$

5 A matriz foi convertida em produtos $x$ produtos na dimensão $(9 \times 9)$. Os elementos $C_{\text {esta }}$ matriz de coeficientes técnicos interprodutos (aij) indicam o quanto se requer do produto $i \mathrm{p} /$ unidade do produto $\mathrm{j}$.

6 A análise sobre os preços finais pode ser feita a partir do impacto sobre os setores produtivos na economia ou diretamente sobre os produtos classificados previamente. Optou-se pela segunda alternativa, visto que assim temos uma visão mais clara do impacto do Imposto Único sobre os preços finais.

7 Ereciso tomar cuidado ao se interpretar o coeficiente do valor adicionado, quando se lida com matrizes de valor, pois nesses casos os coeficientes de valor adicionado têm a mesma natureza de uma proporção, refletindo a participação do valor adicionado no produto (Sanson e Souza, 1992, p.157). 


$$
a_{n 1} x_{1}+a_{n 2} x_{2}+\ldots+a_{M n} x_{n}+y_{n}=x_{n}
$$

Este pode ser apresentado na forma matricial como:

$$
X=Y+A X \text {, que é igual a: (I-A)X }=Y
$$

onde: I representa a matriz identidade; $A$ a matriz de coeficientes técnicos; $X$ o vetor de produção total e $Y$ o vetor de demanda final.

Isolando o vetor de produção total, obtemos a nova equação expressa por:

$$
X=(1-A)^{-1} Y
$$

Esta equação nos mostra que, dados os coeficientes técnicos de produçāo e o vetor da demanda final, é possível determinar a produção necessária, em cada setor, para atender a demanda final. $A$ inatriz $(I-A)^{-1}$, multiplicada por $\mathrm{Y}$, indica os requisitos diretos $e$ indiretos da produção por unidade de demanda final.

\subsection{Os preços dentro do modelo}

Para se montar o sistema de equações de preço no modelo de insumo-produto, parte-se do fato de que o preço, que cada setor de produção da economia recebe por unidade de seu produto, tem que ser igual às despesas totais feitas no decorrer de sua produção. Estas despesas compreendem não só pagamentos de insumos adquiridos da mesma e de outras indústrias, ${ }^{8}$ mas também o "valor adicionado", que representa essencialmente os pagamentos feitos aos setores exógenos.

Assim, para incluir os preços dentro do modelo utilizamos as equações do modelo de Leontieff, quando visto como um modelo de equilibrio geral. Com coeficientes fixos e um produto por setor, a tecnologia determina os preços exclusivamente pelo lado da produção, tornando, assim, possivel discutir preços com um subconjunto de equações do modelo completo (Sanson e Souza, 1992, p.156). As equaçōes de preço do modelo de Leontieff são dadas por:

$$
\begin{aligned}
& P_{1}=p_{1} a_{11}+p_{2} a_{21}+p_{3} a_{31}+\ldots+p_{n} a_{n 1}+v_{1} \\
& P_{2}=p_{1} a_{12}+p_{2} a_{22}+p_{3} a_{32}+\ldots+p_{n} a_{n 2}+v_{2} \\
& =\ldots+\ldots+\ldots+\ldots+\ldots+\ldots \\
& P_{n}=p_{1} a_{1 n}+p_{2} a_{2 n}+p_{3} a_{3 n}+\ldots+p_{n} a_{n n}+v_{n}
\end{aligned}
$$

onde $a_{i j}$ representa o coeficiente técnico dos insumos; $v_{j}$, o coeficiente do valor adicionado e $\mathrm{p}_{\mathrm{j}}$, o preço de cada setor.

A solução destas equaçōes permitirá a determinação dos preços de todos os produtos a partir dos valores adicionados dados (por unidade de produto) em cada setor. A generalização dessas equações, para qualquer número de setores, é imediata. Elas podem ser expressas em termos matriciais como:

$$
\mathrm{P}^{\top}=\mathrm{P}^{\top} \mathrm{A}+\mathrm{V}^{\top}
$$

$8 \quad$ Entre as despesas das empresas no pagamento dos insumos deve-se incluir os produtos importados consumidos ou utilizados ao longo do processo produtivo. 
onde: $\mathrm{P}^{\boldsymbol{T}}$ é o vetor de preços transposto; $\mathrm{A}$ é a matriz de coeficientes técnicos e $\mathrm{V}^{\mathbf{T}}$ é o vetor transposto de coeficientes de valor adicionado.

Resolvendo-se para $\mathrm{P}^{\mathrm{T}}$, a equação de preço pode ser descrita desta forma:

$$
P^{T}=V^{\top}(I-A)^{-1}
$$

Cada elemento da matriz inversa de Leontieff $(1-A)^{-1}$ mostra o acréscimo no preço do setor $j$. por unidade de acréscimo no coeficiente de valor adicionado do setor $i$ (Sanson e Souza, 1992, p.76).

0 uso da equação de preço de Leontieff implica que impostos indiretos sejam totalmente repassados para a etapa de produção ou comercialização seguinte. A partir de uma visão de equilibrio parcial, isto significa dizer que as curvas de oferta de cada indústria são horizontais perfeitamente elásticas (Sanson, 1980, p.248).

Assim, a introdução de um imposto indireto dentro do modelo determinará modificações na equação de preço e, em conseqüência, no preço final dos produtos na economia. Sabendo que o Imposto Único sobre Transações apresenta características de um imposto indireto, podemos examinar os seus efeitos nos preços finais a partir do modelo apresentado.

O Imposto Único ainda pode ser definido como um "imposto em cascata", ou seja, um imposto que incide sobre todas as etapas de produção e distribuição até chegar ao consumidor final. Desta forma, a inclusão de um imposto em cascata, com aliquota única sobre todas as transaçōes, modificará a equação de preço de cada produto.

As novas equações de preços serão descritas da seguinte forma:

$$
\begin{aligned}
& P_{1}=(1+t) p_{1} a_{11}+(1+t) p_{2} a_{21}+\ldots+(1+t) p_{n} a_{n 1}+(1+t) v_{1} \\
& P_{2}=(1+t) p_{1} a_{12}+(1+t) p_{2} a_{22}+\ldots+(1+t) p_{n} a_{n 2}+(1+t) v_{2} \\
& =\ldots+\ldots+\ldots+\ldots+\ldots \\
& P_{n}=(1+t) p_{1} a_{1 n}+(1+t) p_{2} a_{2 n}+\ldots+(1+t) p_{n} a_{n n}+(1+t) v_{n} \\
& \text { Expressas em termos matriciais: } \\
& P^{T}=(1+t) P^{T} A+(1+t) V^{T}
\end{aligned}
$$

onde: $t$ representa a alíquota imposta pelo governo com a implantação deste imposto.

Esta, evidenciando $\mathrm{P}^{\mathrm{T}}$ (o vetor de preços de cada produto), através de algumas operações, pode ser expressa como:

$\mathrm{P}^{\top}=(1+\mathrm{t}) \mathrm{V}^{\top}[1-(1+\mathrm{t}) \mathrm{A}]^{-1}$

Considerando ainda que o imposto incide mais uma vez na transação final do produto, chegamos à fórmula final:

$$
P^{T}=(1+t) P^{T}
$$

onde: $\mathrm{P}_{\mathrm{t}} \mathrm{t}_{\mathrm{e}}$ o vetor de preços dos produtos, considerando a última transação envolvida.

Observe que, como estamos tratando com impostos indiretos, $\mathrm{PT}_{\mathrm{t}} \mathrm{e}_{\mathrm{e}} \mathrm{o}$ vetor de preços obtidos após os repasses do imposto feito em todos os setores produtivos, ou seja, obtido após as transações intermediárias e a última transação envolvida na compra do bem.

Com base neste modelo, temos condições de calcular o impacto da incidência do Imposto Único sobre os preços finais na economia brasileira. 


\section{A INCIDÊNCIA DO IMPOSTO ÚNICO SOBRE TRANSAÇÕES}

A partir do modelo elaborado, buscamos nesta seção projetar a incidência do Imposto Único sobre Transações nos preços finais da economia $\mathrm{Na}$ busca deste objetivo, dividimos esta seção em duas partes. A primeira parte examina a incidência do Imposto Único nos preços finais dos produtos dentro da economia desconsiderando a atual estrutura tributária. Ou seja, retiram-se os impostos indiretos existentes na economia introduzindo o Imposto Único. $\mathrm{Na}$ segunda parte, o trabalho compara estes resultados com os resultados sem a retirada dos impostos indiretos. Esta comparação é relevante, pois alguns setores terão na primeira simulação um impacto muito forte sobre os seus preços finais.

\subsection{0 impacto do IUT sobre os preços finais desconsiderando os impostos existentes}

Retirando os impostos existentes na economia e introduzindo o Imposto Único teriamos o efeito líquido da reforma tributária sob análise. Em outras palavras, com uma reforma tributária que optasse pela aplicação de um Imposto Único na economia, obteríamos apenas o impacto deste imposto sobre os preços, desconsiderando todos os impostos até então existentes.

Neste particular, um ponto importante a ser examinado com a retirada dos impostos indiretos no cálculo da incidência do IUT são os subsídios. Isto é necessário por que há alguns setores que recebem subsídios ao longo do processo de produção, como os setores Agropecuário e Agroindustrial (setores onde geralmente está envolvido crédito agrícola). Nestes setores a retirada dos impostos indiretos (onde também estão os subsídios) e sua substituição pelo Imposto Único implicará um efeito inverso sobre os seus preços.

Isto é fácil de perceber, pois estes setores apresentam sinal negativo na linha de impostos indiretos da matriz de Insumos dos Setores Produtivos (nesta linha também estão colocados os subsidios) Assim, a retirada dos impostos indiretos implica não uma diminuição, mas aumento dos preços finais destes dois setores ${ }^{9}$

Dada esta pequena explicação, apresentaremos os resultados da incidência do Imposto Único nos preços finais com a retirada dos impostos indiretos.

A simulação foi feita a partir da agregação da economia em nove tipos de produtos (classificação formulada pelo IBGE). A partir desta agregação foi possivel obter a tabela 2 que mostra o efeito líquido da incidência do IUT sobre os preços aplicando a alíquota proposta pelo autor.

\section{TABELA 2 - IMPACTO DO IUT SOBRE OS PREÇOS}

9 Se o subsidio fosse apresentado numa linha separada dos tributos existentes, poderiam ter resultados mais precisos, pois neste caso mexeria-se apenas nos tributos sem retirar os subsidios existentes de cada setor produtivo. 
FINAIS DESCONSIDERANDO OS IMPOSTOS INDIRETOS EXISTENTES (\%)

\begin{tabular}{l|c}
\hline \multicolumn{1}{|c|}{ PRODUTOS } & ALIQUOTA DE 2\% \\
\hline 1. Extrativa Vegetal e Agropecuária & 7,33 \\
2. Extrativa Mineral & 3,09 \\
3. Metal-Mecánica & 3,95 \\
4. Química & 3,57 \\
5. Agroindústria & 11,53 \\
6. Outros Produtos industriais & 4,23 \\
7. Construção Civil & $-6,56$ \\
8. Margem de Comércio e Transportes & 1,09 \\
9. Serviços & 1,65 \\
\hline
\end{tabular}

Fonte: Cálculos do autor.

Comparando estes resultados a uma situação anterior, em que o preço final dos diversos produtos na economia era determinado a partir da incidência dos impostos indiretos existentes, constatamos que a aplicação da aliquota de $2 \%$ sobre todas as transações na economia provocará uma significativa alteração dos preços relativos na economia brasileira.

O exame dos valores apresentados na tabela 2 mostra que os prociutos que sofrem uma maior alteração no seu preço final com a aplicação deste imposto são os ligados a atividade de Agroindústria. Estes produtos apresentariam uma variação de $11,53 \%$ no sei preço final com a incidência de uma alíquota de $2 \%$. Já nos produtos de Extrativa Vegetal e Agropecuária, o impacto sobre os seus preços seria maior, em $7,33 \%$ para a alíquota de $2 \%$ Os produtos ligados a outras atividades como Metal-mecânica, Química e Outros Produtos Industriais também sofreriam impactos positivos sobre os seus preços finais com a aplicação do Imposto Único.

Este impacto muito forte sobre o preço final dos produtos ligados a estas atividades, principaimente nas atividades da Agroindústria e Agropecuária, pode ser explicado pela presença de uma parcela grande de subsidios. Como os subsidios são apresentados juntos aos impostos indiretos na tabela de Insumos dos Setores Produtivos (utilizada para o cálculo da incidência), ao retirarmos os impostos indiretos destes prcúutos, estamos também retirandn os subsífios ali incidentes (no saso destes dois setores a incidência do subsídio é maior que a dos impostos, pois os valores expressos são negativos). Assim, a incidência do Imposto Único nestes setores acaba determinando um impacto muito forte sobre os preços finais dos seus produtos.

Por outro lado, os menores impactos sobre o preço final se dariam para as atividades ligadas a Prestação de Serviços, de Comercializaçăo e Transporte e de Construção Civil. Nos setores de Comercialização e Transporte e de Serviços o impacto da impiantação do IUT ainda se daria através de um aumento nos preços dos seus produtos, porém a niveis bem mais baixos dos apresentados nos setores da Agroindústria e Agropecuária e Extrativa Vegetal.

Para o setor da Construção Civil, em específico, os resultados obtidos nos mostram que a retirada dos impostos existentes na economia e a inclusão do IUT determinou uma diminuição dos preços finais dos produtos ligados a esta área. Assim, aplicando uma aliquota de $2 \%$ sobre todas as transações deste setor, o impacto final sobre os 
preços se daria a um nivel $6,56 \%$ mais baixo do que com a incidência dos impostos atuais.

\subsection{O impacto do IUT considerando os impostos indiretos existentes}

A partir destes resultados, poderou-se relevante nesta seção comparar os resultados desta simulação com os resultados da simulação considerando a linha de impostos indiretos. A tabela 3 fornece o impacto do IUT sobre os preços finais considerando os impostos existentes.

TABELA 3 - IMPACTO DO IUT SOBRE OS PREÇOS

FINAIS CONSIDERANDO OS IMPOSTOS INDIRETOS EXISTENTES (\%)

\begin{tabular}{l|c}
\hline \multicolumn{1}{c|}{ PRODUTOS } & ALIQUOTA DE 2\% \\
\hline 1. Extrativa Vegetal e Agropecuária & 5,01 \\
2. Extrativa Mineral & 5,17 \\
3. Metal-Mecânica & 6,05 \\
4. Química & 5,35 \\
5. Agroindústria & 6,40 \\
6. Outros Produtos Industriais & 5,80 \\
7. Construção Civil & 6,05 \\
8. Margem de Comércio e Transportes & 4,59 \\
9. Servicos & 4,69 \\
\hline
\end{tabular}

Fonte: Cálculos do autor.

Comparando os resultados das tabelas 2 e 3 , nota-se que na maior parte dos produtos a simulação, considerando os impostos indiretos existentes, apresentou um impacto maior sobre os preços finais. Este resultado tem a sua lógica, pois nesta simulação incide conjuntamente sobre os preços os imipostos indiretos e a alíquota do Imposto Único.

Entretanto, três setores apresentaram valores bastante diferenciados de uma simuiação para outra. 1)s setores que compreendem os Produtos de Extrativa Vegetal e Agropecuária e Produtos da Agroindústria tiveram um impacto maior sobre os preços quando os imposto indiretos foram retirados. Isto confirma que nestes produtos incide uma quantidade maior de subsídios do que de impostos indiretos.

No setor da Construção Civil as diferenças foram ainda maaiores de uma simulação para a outra. Sem a retirada dos impostos indiretos, o impacto sobre os preços finais dos produtos deste setor foi muito forte, sendo de $6,05 \%$ para a alíquota de $2 \%$. Já para a simulação feita com a retirada dos impostos indiretos, o impacto sobre os preços teria um efeito inverso, diminuindo, em média, os preços dos produtos deste setor em $6,56 \%$.

A partir dos resultados destas tabelas, pode-se formular duas conclusões. A primeira conclusão observa que o impacto sobre os preços, com a substituição dos impostos indiretos por um Imposto Único, determinará na maioria dos produtos da economia um aumento no nivel de preços (apenas nos produtos do setor da Construção Civil haveria uma redução dos preços ao consumidor). Contudo, 
considerando a presença de subsídios em alguns setores, esse aumento não será de forma tão intensa para os Produtos de Extrativa Vegetal e Agropecuária e para os Produtos da Agroindústria.

A segunda conclusão demonstra que o impacto sobre os preços não ocorrerá de forma muito diferenciada entre os diversos setores da economia. Assim, observando a simulação feita sem a retirada dos impostos indiretos para a aliquota de $2 \%$, o impacto do IUT sobre os preços finais variará entre $4,59 \%$ no setor de Margem de Comercialização e Transporte e 6,40\% para os produtos da Agroindústria.

Por fim, objetivando alcançar dados mais conclusivos e ainda mais próximos da realidade, desagregamos as tabelas de Produção e de Insumos dos Setores Produtos, transformando-as em matrizes com 13 linhas e 13 colunas. Esta desagregação foi feita com o objetivo de verificar se uma desagregação de valores de setores produtivos, levando a um maior número de transações efetuadas no modelo, implicaria um impacto maior sobre os preços finais na economia. Feita esta simulaçăo e observado os seus resultados, verificamos que a agregação da matriz de coeficientes técnicos em nove produtos não trouxe prejuizo em nossa análise.

\section{A RECEITA COM O IMPOSTO ÚNICO}

Talvez o tema mais polêmico na proposta de substituição da atual estrutura tributária pelo Imposto Único sobre Transações seja as perspectivas de arrecadação com a sua implantação. $O$ objetivo dos defensores deste imposto é obter, através de uma aiiquota básica de $2 \%$ sobre todas as transações, a mesma arrecadação atual, ou seja, cerca de 80 a 85 bilhões de dólares anuais ( 20 a 25\% do PIB nacional) garantindo a neutralidade da arrecadação. Esse é o volume médio de recursos arrecadados nos últimos anos pelos três niveis de governo e pela previdência social.

Considerando o debate criado entre críticos e defensores deste imposto quanto à viabilidade de se obter esta arrecadação, esta seção buscou projetar, a partir de uma formulação algébrica, a receita que seria obtida com a aplicação deste imposto.

\subsection{A arrecadação que seriá alcançada com o IUT}

Para calcular a arrecadação com o IUT, o cálculo realizado considerou que o imposto incide sobre as transações intermediárias e finais na economia e que tanto o setor privado quanto o setor governamental sofrem com a cobrança do imposto.

Assim, utilizando como instrumental o modelo de relações intersetorias elaborou-se uma fórmula geral para estimar a arrecadação total com este imposto: ${ }^{10}$

$10 \mathrm{Na}$ fórmula abaixo, as exportações foram retiradas do cálculo da receita poí serem consideradas isentas deste imposto. Isto é fácil de entender, pois se um comprador estrangeiro emite um cheque para pagar um vendedor brasileiro, nesta transação não haverá a incidência do imposto e este não será pago pelo exportador. Contudo deve estar claro que embutidos nas exportações incidirá o tributo nas diferentes etapas de produção e comercialização até que o mesmo chegue a esta última transação entre o vendedor nacional e o comprador estrangeiro. 


$$
R=t\left(P^{\top} t A X\right)+t V^{\top} X+t P^{\top}(C+k+G)
$$

onde: $R$ é a receita com o imposto; t é a aliquota do imposto; $A$, a matriz de coeficientes técnicos de produção; $X$, o Consumo intermediário por produto mais a demanda final $(C+G+k+E)$, desconsiderando-se os setores "dummies"; $V^{\top}$ o vetor transposto do valor adicionado nos diferentes produtos da economia; $\mathrm{PT}_{t} \mathrm{o}$ vetor transposto dos preços finais da economia após a incidência do imposto na última transação do produto (até chegar ao consumidor final); $\mathrm{C}$ o consumo pessoal; $\mathrm{G}$ o consumo do governo e $\mathrm{K}$ a formação de capital. ${ }^{11}$

Adotando como fonte de dados para o cálculo da arrecadação a tabela de Insumos dos Setores Produtivos e Demanda Final (IBGE, 1987, p.34), a receita foi calculada para a aliquota proposia pelo autor de $2 \%$. Através desta, alcançou-se uma arrecadação igual a Cr\$46.732 (em milhões de cruzeiros para 1975).

Analisando estes resultados com o PIB calculado também através dos dados da tabela de Insumo dos Setores Produtivos e Demanda Final, ${ }^{12}$ pode-se estimar a carga tributária gue teria esta nova estrutura tributária, comparando-a com a atual carga tributária ${ }^{13}$

Partindo do conceito de que o Produto Interno Bruto (PIB) de uma economia pode ser estimado pelo total da despesa bruta em uso finais de bens e serviços, medida em preços de mercado, menos a importação de bens e serviços, valorados a preços FOB, chegou-se à seguinte identidade (Rosseti, 1992, p.228 - 229):

$$
\mathrm{PIB}_{\mathrm{pm}}=\mathrm{C}_{\mathrm{p}}+\mathrm{C}_{\mathrm{g}}+\mathrm{I}_{\mathrm{b}}+\mathrm{X}-\mathrm{M}
$$

onde $\mathrm{PIB}_{\mathrm{pm}}$ é um escalar que representa o Produto Interno Bruto a preços de mercado, $\mathrm{C}_{p}$ é Consumo Pessoal, $C_{g}$ é Consumo do Governo, $\mathrm{l}_{b}$ é Investimento Bruto, $X$ Exportações e M Importações.

Reinterpretando esta identidade em termos de vetores da matriz de relações interindustriais e aplicando à mesma os novos vetores de preço obtidos com a substituição dos atuais impostos pelo imposto Único (calculados no capitulo 3) pode-se obter o novo PIB calculado através da seguinte fórmula:

$$
\mathrm{PIB}_{p m}=(1+t)\left[P_{t}^{\top}\left(C_{p}+C_{g}+I_{b}\right)-P_{t} T_{M}\right]+P_{t}^{T} X
$$

11 O somatório do Consumo Pessoal(C), Consumo do Governo (G), Formação de Capital(K) e Exportação(E) é igual ao total da demanda final.

12 Observando que as tabelas utilizadas apresentam um detalhamento da conta de produção, apenas enfatizando o aspecto da interdependencia no processo produtivo, é possivel a partir delas chegar às identidades básicas da contabilidade nacional entre renda, produto e despesa. Assim, podemos calcular o PIB a rreços de mercado: $\mathrm{PIBpm}=\mathrm{VBPpb}-(\mathrm{C} .1$ dos setores produtivos $+\mathrm{C}$ dos setores dummies + impostos indiretos liquidos). Este valor é idêntico ao da renda gerada nos setores produtivos, também acrescida desses impostos e a despesa interna bruta (total da demanda final a preços de mercado menos importaçōes) (IBGE, 1987, P.29-32).

13 Embutidas nas exportações acontecerá a incidência do Imposto Único nas diferentes etapas de produção e comercialização até que o produto chegue a esta última transação entre o vendedor e o comprador estrangeiro. Contudo, sobre esta última transação, não há incidência do imposto. Nas importaçōes, contrariamente, a incidência do Imposto Único só ocorrerá na transação final, quando o comprador nacional comprar qualquer produto ou serviço estrangeiro. 
onde t é a aliquota proposta para o imposto e $P_{t}^{\top}$ é o novo vetor de preços com a introdução do Imposto Único.

Adotando esta fórmula para o cálculo do PIB, e aplicando a alíquota de $2 \%$ chegouse ao seguinte resultado: Para a aliquota de $2 \%$ obteve-se um PIB calculado igual a $\mathrm{Cr} \$ 767.686,88$ (em milhões de cruzeiros de 1975)

Sabendo que a arrecadação do imposto, aplicando a alíquota de $2 \%$, alcançou $\mathrm{Cr} \$$ 46.732 em milhões pode-se estimar uma receita equivalente a $6,09 \%$ do PIB anual (dividiu-se a arrecadação com o imposto pelo PIB calculado). Por este resultado, se percebe que os valores seriam insuficientes para cobrir a atual arrecadação tributária que está em torno de $20 \%$ a $25 \%$ do PIB brasileiro.

Além disso, deve-se fazer ressalvas quanto as prováveis mudanças no comportamento dos agentes econômicos após a implantação do imposto. Neste ponto, se soubéssemos com exatidão o valor da elasticidade de transações bancárias poderiamos medir a magnitude das reações dos agentes econômicos à introdução do novo imposto - o economista Marcos C. Albuquerque estima em $20 \%$ a perda de arrecadação derivada dos ajustamentos dos agentes econômicos com a aplicação do imposto (Albuquerque, 1993, p.2).

Desta forma, provavelmente a aplicação deste imposto provocaria uma corrosão na base tributária mediante a desintermediação e dolarização das transaçōes, bem como um incentivo ao uso de papel moeda $e$ de outros tipos de transações diretas por endosso de cheques, escambo ou troca de créditos entre agentes econômicos, sem a participação do sistema bancário.

Esta possibilidade associada a uma possivel integração vertical das empresas determinaria uma arrecadação ainda menor com este tributo, inviabilizando a neutralidade fiscal defendida pelos seus defensores.

\section{A REGRESSIVIDADE COMI O NOVO SISTEMA TRIBUTÁRIO}

Um dos princípios tributários mais requerido por um tributo é o principio da justiça tributária ${ }^{14}$ Este prıncípio nos diz que cada individuo deve contribuir para o fisco de acordo com a sua capacidade contributiva. Isto permite um grau de progressividade maior no sistema tribuiário e uma melhor redistribuição da riqueza gerada na sociedade.

Sob este aspecto, cabe salientar que, normalmente, as caracteristicas de progressividade de um sistema tributário são dadas pelo peso dos tributos diretos na carga tributária incidente sobre os contribuintes.

Contudo isto não é uma regra absoluta, pois é possivel estabelecer uma tributação indireta seletiva sobre bens de consumo típico de altas rendas, dando um conteúdo progressivo a estrutura tributária. É com base neste argumento que os economistas

$14 \mathrm{Um}$ sistema tributário é justo quando a carga tributária se distribui da forma mais equitativa possivel entre os contribuintes. Assim, quanto maior for a capacidade econômica do individuo, maior deve ser a sua contribuição ao fisco. Por outro lado. quanto menor for a sua capacidade econômica, menor deverá ser a sua contribuição. 
favoráveis à implantação do Imposto Único sobre Transações defendem a sua não regressividade.

A progressividade do imposto seria garantida pelo fato de que os consumidores de maior poder aquisitivo adquiririam bens mais elaborados industrialmente, ou seja, bens com um maior nivel de complexidade e com um maior número de etapas ou estágios para sua produção e distribuição. Assim, sobre um computador ou um automóvel a incidència deste imposto será maior que sobre produtos alimentares em geral. ${ }^{15}$

Partindo disto, esta seção busca calcular o grau de regressividade do novo sistema tributário, baseado no Imposto Único sobre Transações. Utilizando o modelo de Relações Intersetoriais pegamos a tabela de Insumos dos Setores Produtivos e Demanda Final (IBGE, 1987, p. 55-76), agora na versão desagregada, e selecionamos as colunas que apresentam o consumo pessoal por produtos desagregado por faixa de renda.

Presumindo a hipótese de que os produtos da Agroindústria e da Agropecuária são os que mais pesam na alocação da renda do assalariado de menor remuneração, o cálculo somou o consumo por faixa de renda com estes dois produtos, determinando a percentagem de gastos nestes produtos para estas diferentes faixas, conforme mostram as Tabelas 4 e 5 .

TABELA 4 - CONSUMO PESSOAL POR FAIXA DE RENDA (SALÁRIO MÍNIMO)

\begin{tabular}{l|r|r|r|r|r|c}
\hline \multicolumn{1}{c|}{ PRODUTOS } & \multicolumn{1}{|c|}{ Até 2 } & \multicolumn{1}{c|}{$2-5$} & $5-10$ & $10-20$ & +20 & TOTAL \\
\hline Extr. vegetal e & & & & & & \\
agropecuária & 2066 & 3248 & 3248 & 1271 & 878 & 9652 \\
Agroindústria & 13808 & 21595 & 14805 & 8555 & 5930 & 64693 \\
Outros Produtos & 27391 & 58644 & 58644 & 55066 & 62624 & 262682 \\
Consumo Total & 43265 & 83487 & 75950 & 64892 & 69432 & 337027 \\
\hline
\end{tabular}

Fonte: Matriz de Relações Intersetoriais -1975, IBGE.

Notas: ${ }^{1}$ Os produtos de Extrativa Vegetal e Agropecuária abiangem os produius-matriz 0101001 a 0410001

${ }^{2}$ Os produtos da Agroindústria abrangem os produtos-matriz 2601001 a 2802001

Os dados da Tabela 4 foram retirados da tabela de Insumos dos Setores Produtivos e Demanda Final (IBGE, 1987, p.34) na versão desagregada (123 setores produtivos $x$ 261 produtos). Estes dados serviram como fonte para obtenção da Tabela 5 que nos dá a percentagem (\%) de gastos por faixa de renda.

15 As faixas de renda mais baixas da sociedade gastam grande parte da sua renda no consumo de bens de primeira necessidade, principalmente artigos de alimentação incluidos na sua cesta básica. 
TABELA 5 - PERCENTAGEM DE GASTOS POR FAIXA DE RENDA

\begin{tabular}{|c|c|c|c|c|c|c|}
\hline PRODUTOS & Até 2 & $2-5$ & $5-10$ & $10-20$ & +20 & TOTAL \\
\hline Extr. vegetal e & & & & & & \\
\hline agropecuária & 4.78 & 3.89 & 288 & 1.96 & 1.26 & 286 \\
\hline $\begin{array}{l}\text { Agroindústria } \\
\text { Subtotal }\end{array}$ & $\begin{array}{l}31.91 \\
3669\end{array}$ & $\begin{array}{l}25.78 \\
2976\end{array}$ & $\begin{array}{l}19.49 \\
2238\end{array}$ & $\begin{array}{l}13.18 \\
15.14\end{array}$ & $\begin{array}{l}8.54 \\
9.81\end{array}$ & $\begin{array}{l}19.20 \\
22.06\end{array}$ \\
\hline Outros bens & 63.31 & 70.24 & 77.62 & 84.86 & 90.19 & 77.94 \\
\hline Consumo total & 100,00 & 100,00 & 100,00 & 100,00 & 100,00 & 100,00 \\
\hline
\end{tabular}

Fonte: Cálculos do autor

A preços de produtor, ${ }^{16}$ isto è, sem impostos, margem de comércio e transporte, percebe-se pela tabela 12 que as classes de renda mais baixas têm um nivel maior de gastos no consumo dos produtos de Extrativa Vegetal e Agropecuária e dos produtos da Agroindústria. A diferença é tão significativa que para os produtos da agroindústria a faixa de renda de até dois salários minimos gasta $31,9 \%$ de sua renda enquanto a faixa de renda com mais de 20 salários minimos gasta apenas $3,54 \%$ de sua renda. ${ }^{17}$ Para os produtos de Extrativa Vegetal e Agropecuária isto também é parcebido, porém não de forma tão intensa.

Remetendo-nos ao inicio do artigo, vimos que, entre os produtos que sofreram maior aumento de preços com a incidência do Imposto Único, destacam-se os produtos da Agroindústria e os produtos de Extrativa Vegetal e Agropecuária. Mais especificamente, conforme mostra a tabela 3, os produtos da Agroindustria sofreriam o maior aumento de preços com a incidência do IUT

Assim, como mostra a tabela 3 , para a aliquota de $2 \%$ os produtos de Extrativa Vegetal e Agropecuária aumentariam os seus preços em $5,01 \%$ e os produtos da Agroindustria em $6,40 \%$. Considerando que o impacto do Imposto Único sobre os preços provavelmente oscilará entre esses valores concluimos que, para os produtos destes setores, a implantação do Imposto Único sobre Transações determinará um aumento significativo nos preços finais

O cruzamento dos dados da tabela $3 \mathrm{com}$ a tabela 5 demonstra que os maiores prejudicados com a implantação do Imposto Úniwo serão os assalariados de mais baixa renda. Isto é fácil de ser explicado, pois os produtos que sofrerão maior impacto sobre os preços finais serão os produtos em que as faixas de renda mais baixas gastam grande parcela de sua renda. De forma inversa as faixas de renda mais altas gastam menor parcela de sua renda nestes produtos

16 A tabela de insumos dos Setores Produtivos e Demanda Final nos traz os valores a preços de produtor e não a preços de consumidor. Isto significa dizer que nos preços dos produtos apresentados nesta matriz não estão incluidos os impostos, a margem de comércio e o transporte

17 Constatando que estes valores foram retirados do ano de 75 , e que de lá para cá a crise económica e social brasileira agravou-se sensivelmente, é provável que o percentual de gastos no consumo dos produtos destes dois setores para as faixas de renda mais baixa tenha aumentado significativamente, fortalecendo as conclusões até agora comentadas. 
Isto nos permite concluir que um sistema tributário baseado essencialmente num Imposto Único sobre transações não atenderá o princípio de justiça fiscal, determinando uma carga tributária mais pesada sobre os indivíduos de menor renda. Contudo cabe aqui uma ressalva; os produtos dos setores de Extrativa Vegetal e Agropecuária e os produtos da Agroindústria são normalmente os que recebem maiores subsídios do governo. Assim, este impacto sobre os preços finais poderia se dar de forma menos intensa, o que provavelmente diminuiria a regressividade do novo sistema tributário.

\section{CONCLUSÕES}

Parece claro para qualquer tributarista que ao longo do tempo os sistemas tributários desenvolveram-se sob influências econômicas, políticas e sociais dos diferentes setores, classes e segmentos da sociedade que individualmente ou coletivamente defendem os seus interesses econômicos.

Contudo, independentemente das pressōes exercidas por estes diferentes grupos, os sistemas tributários devem ser sujeitos a determinados principios que foram elaborados ao longo dos anos pela doutrina financeira.

Assim, considerando a importância de uma nova estrutura fiscal como uma peça essencial dentro da reestruturação econômica e social do país, e seguindo estes princípios tributários fundamentais, examinou-se, entre as diferentes propostas de reforma tributária, o Imposto Único sobre Transações Financeiras (IUT).

Após uma breve revisão sobre os problemas da atual estrutura tributária e os principais aspectos do IUT, o artigo examinou três elementos fundamentais na avaliação de um imposto a incidência do Imposto Único sobre os preços, sua progressividade ou regressividade $e$ as perspectivas de arrecadação deste novo sistema tributário

O primeiro ponto abordado, demonstrou o impacto do IUT sobre os preços finais da economia. A análise deste ponto foi fundamental, pois proporcionou a visualização das mudanças nos preços relativos da economia, advinda da substituição da estrutura tributária

Substituindo os impostos indiretos pelo IUT, observou-se que os impactos sobre os preços mostram-se diferenciados por setores da economia. Assim, os produtos da Agropecuária e de Extrativa Vegetal e os produtos da Agroindústria teriam significativo aumento dos seus preços finais, enquanto nos produtos do setor da Construção Civil a substituição dos atuais impostos pelo Imposto Unico determinaria uma queda nos seus preços.

Contudo, como a retirada da linha de impostos indiretos implicou a retirada dos subsídios junto a cada produto, tornou-se válido calcular o impacto do IUT sobre os preços, considerando os impostos indiretos existentes. Os resultados mostraram um aumento médio dos preços de $5,46 \%$, aplicando a aliquota de $2 \%$. Através desta simulação foi observado que o impacto sobre os preços não se dará de forma muito diferenciada entre os produtos dos diversos setores na economia. 
O segundo ponto examinado neste artigo foram as perspectivas de arrecadação com a implantação do Imposto Único. Utilizando do mesmo instrumental adotado para o cálculo da incidência o trabalho estimou uma receita equivalente a $6,09 \%$ do PIB anual. Com estes dados pode-se concluir que a receita estimada com o Imposto Único sobre Transaçōes mostra-se insuficiente para cobrir a atual arrecadação tributária estimada em torno de $20 \%$ a $25 \%$ do PIB brasileiro Seria necessário a aplicação de uma alíquota maior para alcançar valores próximos da atual arrecadação.

Por fim, não se pode concluir se um imposto é justo socialmente, apenas com base na argumentação teórica. Desta forma buscou-se avaliar a regressividade ou progressividade que se teria substituindo a atual estrutura tributária pelo Imposto Único.

Utilizando dados da matriz de Relações Intersetoriais do IBGE, o trabalho procurou obter uma definição clara quanto à carga tributária que incidiria sobre as diferentes faixas de renda da população com a aplicação do IUT.

Através do cruzamento dos dados, percebeu-se que sobre as faixas de renda mais baixas incidiria uma maior carga tributária. Isto ocorreria, principalmente, pelo fato de que os produtos do setor da Agroindústria (produtos que sofreriam o maior aumento nos preços com a aplicação do IUT) serem os que mais pEsam no consumo da renda das classes mais baixas da população Os resultados demonstraram que este imposto não atenderia o principio da eqüidade, pois sua aplicação determinaria uma carga tributária mais pesada sobre os individuos de menor renda.

O trabalho conclui que, apesar dos resultados desfavoráveis verificados, é inegável algumas vantagens que se teria com a implantação do IUT. Virtudes como simplicidade, clareza e baixo custo de arrecadação certamente seriam advindas com a sua apticação. Entretanto, estas virtudes, apesar de serem pretendidas em todos os sistemas tributários modernos, não se fazem suficientes para atender um sisterna tributário mais justo e equânime. 


\section{BIBLIOGRAFIA}

ALBUQUERQUE, Marcos C. C. de. O imposto único sobre transações. Conjuntura Económica. Rio de Janeiro: FGV, v 45 n.9, p.36-40, set 1991 a.

O Imposto único sobre transações. In Indicadores Econômicos - FEE. Porto Alegre: Fundação de Economia e Estatistica, v.19, n.3, p.56-65, nov. $1991 \mathrm{~b}$.

O Imposto único e o trabalhador. Folha de São Paulo, São Paulo, 15-11-1992, p. 2

A arrecadação do imposto único. Folha de Săo Paulo. São Paulo, 10-7-1993, p.2.

A MARGEM da Reforma Fiscal. Conjuntura Económica. Rio de Janeiro: FGV, p. 9-11, jun. 1992.

CARGA TRIBUTÁRIA EM QUESTÁO. In: Carta de Conjuntura da FEE. Porto Alegre, n. 1, p 5, maio, 1992.

CUNHA, Carlos B. da O Imposto único sobre transações no Brasil. Porto Alegre: UFRGS, 1992 (Trabaiho de Diplomação).

DECÁLOGO de uma boa reforma fiscal. Conjuntura Económica. Rio de Janeiro: FGV, p.7-10, jul. 1991.

DORFMAN, R., SAMUELSUN, P. A., SOLOW, R. Linear programming and economic analysis. New York: McGraw-Hill, 1958.

ERIS, Ibrahim. Distribuição de renda e o sistema tributário no Brasil. In: ERIS, Cláúdia C Finanças Públicas. São Pauto: FIPE/PIONEIRA, 1983.

FONTENELE E SILVA, Paulo Aspectos tecnológicos da estrutura industrial brasileira. Rio de Janeiro: BNDES, 1980.

FRIEDLAENDER, Ann (1967). Indirect taxes and relative prices. Quartely Journal of Economics, v.81, n.322, p. 125-140, feb., 1967.

HADDAD, P.R. Contabilidade social e economia regional. Rio de Janeirc, Zahar, 1976.

IBGE, Matriz de Relações Intersetoriais - 1975. Fundação IBGE. Rio de Janeiro, 1987.

LEONTIEFF, Wassily. A Economia do insumo-produto. São Paulo: Abril Cultural, 1983

LONGO, Carlos A Finanças públicas: uma introdução. São Paulo: IPE.USP, 1984.

. Pacote emergencial e as mudanças estruturais. Informações FIPE, São Paulo, n.133, p. 8-10, set 1991.

MENEGHETTI NETO, Alfredo Imposto único sobre transações: algumas consiḑrações Indicadores Económicos - FEE, Porto Alegre. FEE, v.19, n. 3, p.127-137, nov. 1991.

MING, Celso. As confusões do ajuste fiscal Jornal da Tarde, São Paulo, 18-01-93, p. 2.

PITA, Claudino Uma alternativa duvidosa. Coniuntura Económica, Rio de Janeiro FGV, v. 45, n 9 , p.41-43 set 1991.

ROSSETI, José P. Contabilidade social. $7^{\mathrm{a}}$ ed. São Paulo: Atlas, 1992.

SANSON, João $R$. Incidence of the substitution of a value-added tax for a turriover tax. The case of Brazil. Recife. PIMES-UPE, 1980

e Souza, Nali de J. Produtos-chave no encadeamento de preços. In: SOUZA, Nali de J. A Economia da inflação, Porto Alegre: UFRGS, 1992, p. 156 a 176.

ZOCKUN, Maria H. Por Onde começar a reforma do Estado? In: Informações FIPE São Paulo, n. 131, jun. 1991, p.7-8.

Uma contribuição ao debate da reforma fiscal. In: Informações FIPE, São Paulo, n 147, p.24, nov.-dez, 1992

YAN, C. Introduction to input-output economics. New York: Rinehart \& Winston, 1969. 


\section{ABSTRACT \\ THE BRAZILIAN TRIBUTARY SYSTEM AND THE PROPOSAL OF THE SINGLE TAX OVER TRANSACTIONS}

Evaluating the picture of the crisis that the Brazilian state is undergoing and the urgency in the structural reforms which can improve its efficiency and redraw its performance in the economy, the work searches to examine the proposal of a tributary reform that aims to create a single tax. In this study, the work searches to quantify, from a mathematical model, the impact of this tax over the final prices, the revenue coming from its aplication and the degree of the system regressivity with its implantation. 